\title{
Effectiveness of Rhythmic play on the Attention and Memory functioning in Children with Mild Intellectual Disability (MID)
}

\author{
Abbas Taghipour Javan*, Salar Framarzi, Ahmad Abedi, Fahime Hassan Nattaj \\ Department of Children with Special Needs, University of Isfahan, Isfahan, Iran \\ *E-mail address: abbas.javan.t@gmail.com
}

\begin{abstract}
The present paper aimed at investigating the effects of rhythmic play on ID (Intellectually Disabled), children's attention and memory functioning at the age range of 9-16 years. Research measures included Raven Colored progressive matrixes for children and Canners neuropsychological test and Vinland adaptive behavior scale questionnaire. Statistical population comprised all ID students in elementary schools in the city of Esfahan in the Iranian academic year 2011. The research sample consisted of 20 children with intellectual disability selected by using multistage random sampling. Then, homogeneous in sensory and motor skills, participants were divided into two groups of ten: control and experimental. After receiving the parental consent, the researchers applied rhythmic movements to experimental group twice a week 45 minutes for each session for three months as an intervention program. Eight rhythmic movements (play) were employed in this research. The results revealed that rhythmic movements would affect attention problems (focus of attention, sustained attention, shifting attention, divided attention and attention capacity), general attention, memory (shortterm, long-term, working), as well as general learning problems in educable children with intellectual disability according to their performance scales.
\end{abstract}

Keywords: Memory; Attention; Rhythmic play; Mild intellectual disability

\section{INTRODUCTION}

According to the different international statistics of many research-based studies, approximately $2.5 \%$ to $3 \%$ of all children at school age are likely to suffer significantly from intellectually developmental disorders (Louhiala, 2004; Fryers, 2006; Carr et. al; 2007), which undoubtedly contributes to children's inability to use normal education programs. Today, people are well aware of differences between normal and intellectually disabled children. ID is not a mere description of an individual's limitations, but it is defined as a deficient interaction between an individual and his/her social environment (Kaplan \& Sadocks, 2007). Given that most children with learning disabilities such as those with intellectual disorders may have problems with meta cognition and memory, especially with short-term memory, it is obvious that a deficit in any of these skills can have a major impact on these children's ability to arrange, evaluate and organize information (Kakavand, 2006). Besides, there are abundant cases of inattentiveness, lack of concentration and disruptive behaviors among these children 
that weigh down their ability to perceive, to retrieve, to recognize, to learn, and to form concepts and information.

Attention is defined as a set of complex cognitive processes that includes focusing on a goal or working on it, maintaining or sustaining information, and staying vigilant for a long period of time, and encoding the characteristics of a stimulus, as well as shifting focus from one goal to another (Seidman \& et al, 2006). based on the theoretical principles, components of attention are termed as regulation of excitement and care, selective attention, sustained attention, attention span or divided attention, inhibition, and control of behavior (Seidman \& et al, 2006; Valera \& Seidman, 2006; Meltzer, 2007). Focus of attention refers to the ability to direct an individual's attention to a particular stimulus, while sustained attention indicates the ability to maintain attention during a repetitive or continuous activity. Selective attention is the ability to focus on target stimuli and stop producing response to none- target stimuli. On the other hand, shift of attention (attentional shift) occurs when attention moves from one stimulus to another one. Studying divided attention, it can enlighten us as to the limitations of individual's processing systems on one hand, and on their attentional mechanisms and abilities on the other hand (Eysenck \& Keane, 2002).

Bergen \& Mosley (1994) studied the attention process and attentional shift among normal and ID individuals(based on Stroop test). They concluded that compared to the normal students, the ID ones were more likely to have an increased interference effect when Stroop test was administered and were more prone to errors when it came to shift shifting their attention that required unconscious skill enabling them to give correct answers.

Memory is the process in which information is encoded, stored and retrieved(Swanson \& Graham \& Harris, 2003). In fact, in order for the memory system to function properly, there are three essential stages: encoding, storing and retrieving information which constantly interact with each other in real life. The first stage of memory system is encoding, -also termed as input and registration- a process through which information is registered. As this information tend to have different characteristics, hence in any encoding process, given certain characteristics may be registered to suit the type of information (verbal, visual, and practical) in a specific part of the memory(short term-long term)either unconsciously or consciously (Baddely, Kopelman \& Wileson, 2002; Wileson, 2009). Storage or storing (consolidation) is the second memory stage or process, which occurs after encoding and before retrieval(recalling) processes, This entails that we store the encoded information or input data in our mind in order to reuse it in certain circumstances. Retrieval is a stage where by the stored information, which has under gone the two first steps, is called back in response to some cue for use in a process or activity (Baddely, Kopelman \& Wileson, 2002; Wileson, 2009).

Studies on intellectually disabled children showed that they exhibit deficits in their shortterm and long-term memory as compared to their normal counterparts. Sometimes, learning takes more time and requires more repetition for ID children. Additionally, these children's skills may need to be adapted to their learning level. Nevertheless, every intellectually disabled child is able to learn, develop and recall information like other normal children virtually (Homm, 2006).

With the purpose of finding the most influential therapy techniques, several studies have examined the effectiveness of different methods (Farmer \& et al, 2002). Play therapy, among all methods, has been widely used among clinicians, therapists, and researchers to treat a wide range of emotional and behavioral problems for several decades and its effectiveness has been confirmed (Bratton \& et al, 2005). But there has been one aspect of play researchers less appeal to which is the use of dance-oriented play (rhythmic movements) for children with intellectually disability. 
Children with ID are in dire need to receive -and indeed ought to have- treatments that involves play, which has a significant role in intervention for research studies have reflected the impact of play on cognitive, social, emotional, motor skill functioning, language learning, and development, creativity and problem solving (Hamm, 2006). It is highly important to consider the merits of that specific property of play, along with the optimal use of unique opportunities play can offer for intellectually disabled children to convey educational messages, expand cognitive functions, develop motor skills, deepen social responsibility, and control behaviors. Not only does play have an effect on the development of children's cognitive ability, but it also affects the physiological structure of their brains (Campbell, 2008). Rhythm, particularly of music and of play, is considered very in fluential as a part of different cultures and human education (Michalowski \& Kozima, 2007). The integration of rhythmic movements and play with rhythmic and harmonic songs, lyrics, and music will lead to the increased efficacy of play therapy method on children (Raafee, 2003), especially on those who reflect the lowest level of physical, intellectual and social reactions (including intellectually disabled and autistic children) (Massion, 2006). Research literatures and articles on ID individuals indicate that the use of music as a therapeutic approach is provided for fulfilling the needs of these groups. There are different reasons to apply music in these groups, such as developing social adaptation, increased focus, enhancement and coordination, self control, emotional stability, motivation, and achieving success (Sadatpur \& Mansour, 2003).

These days, some scientific studies, in particular, show the effect of play and rhythmic exercises (Kenya \& Masal, 2004). While doing rhythmic movements and play, children implicitly learn many cognitive and educational concepts and themes because of the upbeat and rhythmic one, harmony, and liveliness of such movements and play that come together with music. Such a learning process has a remarkable effect on intellectually disabled children (Rafee, 2003).

Several studies suggest that cognitive performance and flexibility of the brain are associated with sports and motor activities (Goldshtrom \& et al, 2010). In their study, Haravand Khani et al. (2008) examined the effect of musical activities on short - term memory in students with intellectual disability. Thirty six intellectually disabled girls at the spanning age from 12 to 19 of $4^{\text {th }}$ and $5^{\text {th }}$ grades in the elementary schools participated in their research. Experimental group was exposed to musical intervention consisted of music and rhythmic movements (dance- oriented play). Following the analysis of data, they concluded that performing activities accompanied by music had a positive effect on intellectually disabled students' short-term memory.

Kazemi and Abedi (2011) investigated the effects of aerobic training on executive functions and attention in children with neuropsychological learning disabilities. Their findings showed that to train these children to do aerobic exercise would improve their executive functions and attention. Yukselen et al. (2008) examined the effect of physical training on ID children's motor skills. Twelve children in the age range of 3 to 6 have participated in 26 practice sessions. The results from their survey indicated that there were significant differences among balancing, running, jumping in pre-test and post-test in the participants. Consequently, their findings support the positive effect of basic motor skills exercise for motor development in ID children.

Given that cognitive skills such as memory and attention in children with intellectually disability are less common than that of their normal counterparts, it is highly important to study the effectiveness of rhythmic exercises like joyful play on children cognitive growth. The present study aimed to probe into the effects of rhythmic movements (dance-oriented) on the 
quality of intellectually disabled students' attention and memory studying in elementary schools in the city of Esfahan.

\section{RESEARCH METHOD}

The experimental method with a pre- test and a post- test design was used in this study accompanied by a control group. Statistical population comprised all intellectually disabled students in elementary schools in the city of Esfahan in the Iranian academic year 2011. Twenty children with intellectually disability from two special schools (10 students from each school) among five educational districts were randomly selected by using multistage cluster sampling as the research sample. Homogeneous in sensory and motor skills, participants were divided into two groups (each with randomly 10 students): control and experimental. Raven IQ test, Vinland adaptive behavior scale questionnaire, and Canners neuropsychological test were used. Then, the sample was matched by Raven IQ test, Vinland adaptive behavior scale questionnaire. After received parental consent, the researchers gave rhythmic movements (dance- oriented) to experimental group twice a week 45 minutes for each session for three months as an intervening program. Eight rhythmic games were used in this research. Moreover, synchrony and easy to difficult steps were considered in this play therapy. After the type of music and the kinds of songs and lyrics were chosen, they have been approved by three experts and university professors. At the final step, they were conducted with the help of physical education teachers in schools. The followings are some of the applied rhythmic movements in brief:

1) Rhythmic line play: in this play, the child should run on a straight line according to the rhythm of the music presented in the song and should also follow the commands given in the song(such as jump, sit down, hop, pair jump and....).

2) Lozenge move: the child should move on the color-coded lines of lozenge according to the pattern which has been shown by his/her teacher accompanied by music. In the first run, the child must perform these moves without music, just singing the song on his/her own.

3) Sound play: the child will demonstrates or simulates the movement of objects when they hear their sound in their surrounding area. For example, as soon as they hear the sound of a plane or a train, they start moving like one.

4) Colored ball play: In this play, first colored strips in different sizes are spread on the floor, then, small balls with the same colors as strips are placed along the strips at different distances. When the song or music starts, the child should pick up a small ball, color of which is mentioned in the song, and then hop along the strip and finally throw the ball into the basket placed at the end of each strip. The number of balls that the child should pick up is added as the music goes on.

5) Play of shapes on the floor: different shapes (circle, square and .....) are put in different parts of the floor. While the child is singing the song along with the recorder simultaneously, s/he should start moving towards the shape mentioned in the song. Animal shapes can be used in this play.

6) Chess board game: the child is asked to stand on a chess-like board. Then s/he starts hopping or pair- jumping in different directions as soon as she/he hears the instruction 
given in the recorder through music and song (two squares up, three squares right and......).

7) Numbers table game: colored numbers are arranged inside the perimeter of a square randomly. As soon as the numbers have been mentioned in the song by using the name of animals or flowers, the child should run towards or leap into the required number.

8) Strip-shape play: the child is asked to walk on the strip and to do the required activity when $\mathrm{s} /$ he gets to the point, where different shapes were placed, based on his/her teacher's instruction (the number of teachers' clapping). The number of shapes will be gradually increased in this play.

Post-test has been carried out on both groups by administering Canners neuropsychological test. For descriptive analysis, the obtained data were transferred to SPPS spread sheet; then, multivariate analysis of covariance (MANCOVA) was used.

\section{INSTRUMENTATION}

\section{1. Raven Colored progressive matrixes (APM) for children}

This test was revised by Raven in 1956. It was designed to measure children reasoning ability in the 3 - 11 age range. It includes 36 geometric shapes grouped in three sets as A, B, AB. Scoring procedure of Raven's test for children is based on the score of zero and one. Actually, the minimum score that a child can get in this test is zero and the maximum one is 36. Raven \& Summers (1968) reported that the retest coefficient of his revised test seemed to be 0.60 and 0.80 for children at the age of 6.5 to 9.5 in one year showing sensitivity to the fluctuations of the output of intellectual activity in early childhood.

\section{2. Vinland adaptive behavior scale questionnaire}

The scale has 117 items using a year-scale format in the record booklet. For each item, the required data is gathered it her through interview with well-informed people or through each of the participant herself/his self rather than test conditions. This scale is based on what a person is able to do in everyday life. Farmarzi \& et al reported the reliability of 0.93 for subscale of VABS based on Cronbach's alpha. Annstazi (1976) reported the validity of 0.81 and reliability of 0.71 for this scale. They believed that the related validity and reliability are deemed to be stronger in early age especially in intellectually disabled groups.

\section{3. Canners neuropsychological test}

Canners designed this test in 2004 to assess some neuropsychological skills such as attention, memory, sensation and motor activities, as well as spatial visual processing across four spectrums (invisible to very rich) and it is used for children at the age range of 5 to 12 years. Jadidi \& Abedi, (2011) translated this questionnaire into Persian language and extracted its norms in 20011. Internal reliability coefficient ranged between 0.75 and 0.90 while re- test validity coefficient with an eight- week interval was reported to be 0.60 to 0.90 . To measure the construct validity of Canners questionnaire, all items were analyzed. Similarly, their differential validity was strongly confirmed by statistically analyzing the quality of the questionnaire as a tool for differentiating people with ADHD from those who are normal and from other clinical groups. Jadidi \& Abedi (2011) stated that its construct validity was good. Also, the reliability of this tool seemed to be 0.72 by using Cronbach's alpha. 


\section{FINDINGS}

Descriptive and inferential statistics were used to analyze data. In view of the equality of variances in Wilks Lambda test and the normality of the data, parametric tests were applied to the research data.

Table 1. Descriptive statistics showing "attention function" scales for both control and experimental groups from pre-test and post-test.

\begin{tabular}{|c|c|c|c|c|c|c|}
\hline \multirow{2}{*}{$\begin{array}{c}\text { Function of } \\
\text { attention }\end{array}$} & Groups & numbers & \multicolumn{2}{|c|}{ Pre-test } & \multicolumn{2}{|c|}{ Post-test } \\
\cline { 4 - 7 } & & Mean & $\begin{array}{c}\text { Standard } \\
\text { Deviation }\end{array}$ & Mean & $\begin{array}{c}\text { Standard } \\
\text { Deviation }\end{array}$ \\
\hline \multirow{2}{*}{$\begin{array}{c}\text { Selective } \\
\text { attention }\end{array}$} & Experimental & 10 & 3.30 & 1.59 & 2.20 & 1.16 \\
\cline { 2 - 7 } & control & 10 & 3.20 & 1.54 & 3.00 & 1.21 \\
\hline \multirow{2}{*}{$\begin{array}{c}\text { Sustained } \\
\text { attention }\end{array}$} & Experimental & 10 & 5.10 & 2.78 & 3.10 & 2.31 \\
\cline { 2 - 7 } & control & 10 & 5.20 & 2.33 & 5.30 & 1.41 \\
\hline \multirow{2}{*}{$\begin{array}{c}\text { Shift of } \\
\text { attention }\end{array}$} & Experimental & 10 & 5.50 & 1.85 & 3.70 & 1.91 \\
\cline { 2 - 7 } & control & 10 & 5.40 & 1.75 & 5.20 & 1.62 \\
\hline \multirow{2}{*}{$\begin{array}{c}\text { Divided } \\
\text { attention }\end{array}$} & Experimental & 10 & 6.80 & 1.44 & 3.60 & 1.34 \\
\cline { 2 - 7 } & control & 10 & 5.40 & 2.06 & 5.30 & 2.18 \\
\hline \multirow{2}{*}{$\begin{array}{c}\text { Attention } \\
\text { span }\end{array}$} & Experimental & 10 & 7.00 & 1.74 & 4.20 & 1.55 \\
\cline { 2 - 7 } & control & 10 & 6.80 & 2.41 & 7.00 & 2.32 \\
\hline \multirow{2}{*}{$\begin{array}{c}\text { Total } \\
\text { attention }\end{array}$} & Experimental & 10 & 27.40 & 9.35 & 16.80 & 8.25 \\
\cline { 2 - 7 } & control & 10 & 26.00 & 10.05 & 25.80 & 9.70 \\
\hline
\end{tabular}

As shown in Table 1, the mean scores of selective attention, sustained attention, shift of attention, divided attention, attention span and total attention from pre-test and post-test in experimental group decreased from 3.00 to 2.20 , from 5.10 to 3.10, from 5.50 to 3.70, from 6.80 to 3.60 , from 7.00 to 4.20 and from 27.40 to 16.80 respectively indicating an improvement in experimental group's performance of attention scales and total attention. 
Table 2. Descriptive statistics showing memory function for both control and experimental groups obtained from pre-test and post-test.

\begin{tabular}{|c|c|c|c|c|c|c|}
\hline \multirow{2}{*}{$\begin{array}{c}\text { Memory and } \\
\text { learning } \\
\text { scales }\end{array}$} & Groups & \multirow{2}{*}{ numbers } & \multicolumn{2}{|c|}{ Pre-test } & \multicolumn{2}{|c|}{ Post-test } \\
\cline { 4 - 7 } & & & mean & $\begin{array}{c}\text { Standard } \\
\text { deviation }\end{array}$ & mean & $\begin{array}{c}\text { Standard } \\
\text { deviation }\end{array}$ \\
\hline \multirow{2}{*}{$\begin{array}{c}\text { Short-term } \\
\text { memory }\end{array}$} & Experimental & 10 & 7.50 & 3.92 & 4.60 & 2.23 \\
\cline { 2 - 7 } & Control & 10 & 7.20 & 4.21 & 7.40 & 4.20 \\
\hline \multirow{2}{*}{$\begin{array}{c}\text { Working } \\
\text { memory }\end{array}$} & Experimental & 10 & 5.40 & 2.61 & 3.50 & 2.15 \\
\cline { 2 - 7 } & Control & 10 & 5.20 & 3.27 & 5.10 & 3.21 \\
\hline \multirow{2}{*}{$\begin{array}{c}\text { Long-term } \\
\text { memory }\end{array}$} & Experimental & 10 & 6.40 & 3.56 & 4.30 & 3.17 \\
\cline { 2 - 7 } & Control & 10 & 6.50 & 3.62 & 6.60 & 3.80 \\
\hline \multirow{2}{*}{$\begin{array}{c}\text { General } \\
\text { learning }\end{array}$} & Experimental & 10 & 4.40 & 2.21 & 2.70 & 1.96 \\
\cline { 2 - 7 } & Control & 10 & 4.20 & 2.16 & 4.20 & 2.16 \\
\hline \multirow{2}{*}{$\begin{array}{c}\text { Total } \\
\text { memory }\end{array}$} & Experimental & 10 & 29.60 & 18.50 & 18.80 & 11.85 \\
\cline { 2 - 7 } & control & 10 & 28.85 & 16.55 & 29.10 & 16.70 \\
\hline
\end{tabular}

Table 2 shows that the mean scores of short-term memory, working memory, longtermmemory, general learning and total memory decreased from 7.50 to 6.40 , from 5.40 to 3.50 , from 6.40 to 4.30 , from 4.40 to 2.70 , and from 29.60 to 18.80 respectively in experimental group based on the results from pre-test and post-test indicating an improvement in experimental group's performance of memory function scales and total memory.

Table 3. Results from Laven's test verifying the assumption about theequality of variances for two groups.

\begin{tabular}{|c|c|c|c|c|}
\hline Variables & F & $\begin{array}{c}\text { Freedom of } \\
\text { denominator }\end{array}$ & $\begin{array}{c}\text { Freedom of } \\
\text { numerator }\end{array}$ & $\begin{array}{c}\text { Significance } \\
\text { level }\end{array}$ \\
\hline $\begin{array}{c}\text { Attention } \\
\text { problems }\end{array}$ & 0.843 & 1 & 18 & 0.371 \\
\hline $\begin{array}{c}\text { Memory function } \\
\text { and learning }\end{array}$ & 0.130 & 1 & 18 & 0.723 \\
\hline
\end{tabular}

As observed in Table 3, the assumption about equality of variances for two groups related to two variables attention problems and memory function and learning- is confirmed. Moreover, the values of variances for two groups are equal in the society and yield no significant difference. Consequently, when Levin's test shows no significance with confirmed assumption, covariance analysis on research results can be used to study the research hypotheses. 
Table 4. Results from MANCOVA analysis showing the effect of rhythmic exercises on children's attention problems for both control and experimental groups.

\begin{tabular}{|c|c|c|c|c|c|c|c|c|}
\hline$\frac{\tilde{e}}{\tilde{E}}$ & Source of changes & $\begin{array}{l}\text { Sum of } \\
\text { the roots }\end{array}$ & $\begin{array}{l}\text { Degree } \\
\text { of } \\
\text { freedom }\end{array}$ & $\begin{array}{l}\text { Mean of } \\
\text { the roots }\end{array}$ & $\mathrm{F}$ & Significance & Effectiveness & $\begin{array}{c}\text { Statistical } \\
\text { powers }\end{array}$ \\
\hline \multirow{6}{*}{ 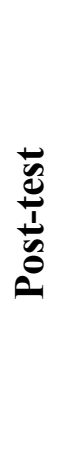 } & Focus of attention & 8.322 & 1 & 8.322 & 29.814 & 0.00 & 0.69 & 0.98 \\
\hline & sustained attention & 25.012 & 1 & 25.012 & 24.210 & 0.00 & 0.66 & 0.99 \\
\hline & Shift of attention & 26.365 & 1 & 26.365 & 18.096 & 0.01 & 0.62 & 0.99 \\
\hline & Divided attention & 8.844 & 1 & 8.844 & 7.241 & 0.02 & 0.38 & 0.68 \\
\hline & Attention span & 20.992 & 1 & 20.992 & 11.236 & 0.00 & 0.52 & 0.90 \\
\hline & Total attention & 421854 & 1 & 421854 & 27.548 & 0.00 & 0.65 & 0.99 \\
\hline \multirow{6}{*}{ 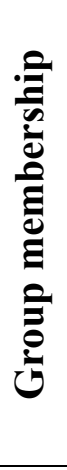 } & Focus of attention & 1.312 & 1 & 1.312 & 4.586 & 0.04 & 0.27 & 0.56 \\
\hline & Sustained attention & 6.146 & 1 & 6.146 & 5.645 & 0.03 & 0.31 & 0.63 \\
\hline & Shift of attention & 1.566 & 1 & 1.566 & 1.521 & 0.01 & 0.08 & 0.19 \\
\hline & Divided attention & 16.854 & 1 & 16.854 & 12.052 & 0.00 & 0.50 & 0.94 \\
\hline & Attention span & 26.370 & 1 & 26.370 & 11.542 & 0.00 & 0.52 & 0.92 \\
\hline & $\begin{array}{l}\text { Total (whole) } \\
\text { attention }\end{array}$ & 318.953 & 1 & 318.953 & 20.375 & 0.00 & 0.58 & 0.99 \\
\hline$\frac{\tilde{e}}{\tilde{J}}$ & Source of changes & $\begin{array}{l}\text { Sum of } \\
\text { the roots }\end{array}$ & $\begin{array}{l}\text { Degree } \\
\text { of } \\
\text { freedom }\end{array}$ & $\begin{array}{c}\text { Mean of } \\
\text { the } \\
\text { roots }\end{array}$ & $\mathrm{F}$ & Significance & Effectiveness & $\begin{array}{c}\text { Statistical } \\
\text { powers }\end{array}$ \\
\hline \multirow{5}{*}{ 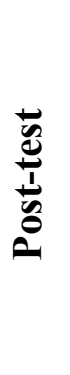 } & Short-term memory & 79.827 & 1 & 79.827 & 60.264 & 0.00 & 0.81 & 1.00 \\
\hline & Working memory & 26.491 & 1 & 26.491 & 44.306 & 0.00 & 0.78 & 1.00 \\
\hline & Long -term memory & 47.012 & 1 & 47.012 & 44.519 & 0.00 & 0.92 & 1.00 \\
\hline & General learning & 50.832 & 1 & 50.832 & 129.439 & 0.00 & 0.92 & 1.00 \\
\hline & Total memory & 286.754 & 1 & 286.754 & 195.211 & 0.00 & 0.94 & 1.00 \\
\hline \multirow{5}{*}{ 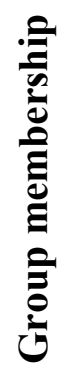 } & Short-term memory & 26.652 & 1 & 26.652 & 20.560 & 0.00 & 0.62 & 0.99 \\
\hline & Working memory & 7.739 & 1 & 7.739 & 11.308 & 0.00 & 0.50 & 0.98 \\
\hline & Long -term memory & 16.168 & 1 & 16.168 & 13.945 & 0.00 & 0.46 & 0.92 \\
\hline & General learning & 3.568 & 1 & 3.568 & 7.363 & 0.01 & 0.32 & 0.71 \\
\hline & Total memory & 216.506 & 1 & 216.506 & 32.063 & 0.00 & 0.73 & 1.00 \\
\hline
\end{tabular}


The differences between the means of post-test scores of children's attention problems have been found significant $(\mathrm{P} \leq 0.05)$ for both control and experimental groups after the effect of per-test was controlled. Hence, based on data in Table 3 and considering the pre-test scores as supporting(auxiliary) variable, it can be inferred that rhythmic exercises can effectively reduce the attention problems of attention function's scales (focus of attention, sustained attention, shift of attention, divided attention, attention span) and the total attention in intellectually disabled children in the elementary school. In view of eta square value and effectiveness of rhythmic play, we can argue that 58 percent of these changes were derived from the effect of rhythmic play on attention problems in experimental group.

Results from covariance analysis in Table 4 revealed that as pre-test effect was controlled, the differences among means of post-test scores showing the function of memory scales (short-term, active and long term memories) and general learning in intellectually disabled children has appeared to be significant for both control and experimental groups $(\mathrm{P} \leq$ 0.05). Therefore, by regarding pre-test scores as asupporting (auxiliary) variable, we can conclude that rhythmic play affect the problems related to memory scales and learning and total memory in ID children. Based on the eta square, it can be said that $73 \%$ of the changes are the result of the effect of rhythmic movements on memory problems amongst educable children with intellectual disability.

\section{DISCUSSIONS AND CONCLUSIONS}

There has been an increasing amount of data provided by several researches that proved the relation of cognitive functioning and flexibility of the brain to play and physical movements (Goldshtrom \& et al, 2010). There are several researches dedicated to the present contribution, the most important of which are considered to be the ones carried out by Davis \& et al (2007) and Coe \& et al (2006), which have tried to shed light on the possible effects of rhythmic exercises(dance-oriented) on intellectually disabled children's attention and memory problems at the age range of 9 to 16 years.

The research finding sun veiled that rhythmic exercises would affect the attentional problems (focus of attention, sustained attention, shift of attention, divided attention, and attention span) and total attentional problem in educable children with intellectual disability in terms of their performance scales. The existing ideas of attention deficit are based on the fact that intellectually disabled individuals' attention span are mainly at the lower level than that of normal students which makes intellectually disabled children unable either to shift their attention to different phenomena or to pay attention to different aspects of a task. These findings were consistent with those obtianed by Shalev \& Yehoshua \& Merorach (2007), Carmeli\& et al(2008),Piek\& et al. (2007), Kaplan \& Steele (2005), Robb (2003) and Kazemi $\&$ Abedi (2011). Conductinga study on 12 pre-school children, Robb (2003) concluded that children's attention was significantly at the higher level in musical- based sessions than playbased sessions. Keita Kamijo \& et al. (2008) investigated the impact of rhythmic movements on teenagers' cognitive functions indicating that cognitive functions, especially attention and memory quality, would grow by doing rhythmic movements. Leisman \& Melillo (2010) inferred that continuous training in physical exercises would positively improve attention amongst children with hyper-activity / attention deficit.

In defining the assumption of improved attention in those children, it may be concluded that the improvement of child's attention is largely related to the child's life experiences. Hence, by enriching the environment and preparing a suitable ground for physical and group 
play, on one hand, probably we can make it possible for intellectually disabled children to grow and improve, and on the other hand, due to the significant role music plays in the context of the rhythmic play, attentional improvement is likely to be attributable to musical functioning and its effectiveness on attention levels. not only does the teaching of music has a great effect on the formation and activity of brain cortex-since there exist different sensory pathways- part of which is the consequence of neurological limitations in intellectually disabled children, but the use of music and rhythm can also increase and expand the nerve branches when done in a form of rhythmic/ dance-oriented play. In fact, long-term sensory stimulation increases the brain synopses and ultimately leads to higher sensory perception. Reticular activating system is an area in the brain that plays an important role in attention al performance, emanating from the lower part of the brain-brainstem, and makes our brain aware and ready to receive information. The role of this system in controlling sustained attention, inhibition, programming, organization and behavioral classification is indispensable. Studies on basal ganglia showed that voluntary motor and muscular activities can improve the system functioning in different groups (Alizadeh, 2004). As a result, rhythmic exercises help intellectually disabled children do voluntary motor activities by which they can further enhance the system functioning and its role in motor coordination leading to an improvement in the performance related to attention scales.

Results from Table 4 suggested that after controlling the effect of pre-test, the researchers found that differences among the mean scores of post-test related to memory scales (shortterm, long-term, and working memory) and general learning in intellectually disabled children were significant $(\mathrm{P} \leq 0.05)$ for both control and experimental groups. Consequently, by considering the pre-test scores as a supporting(auxiliary) variable, it can be concluded that rhythmic play has a remarkable effect on learning, memory, and total memory problems in those children.

The findings of this paper were in agreement with the research results from the work by Kaita Kamijo \& et al. (2008), Whittey \& Ball (2002), Usefi \& et al. (2011). Sutoo \& Akiyama (2003) stated that regular physical activity would significantly improve memory functions, and then increase learning ability owing to the moderate adaptation of central nervous system, especially hippocampus.

In further clarifying the research findings, it is worth noting that the existence of musical aspect in rhythmic play will result in establishing and enhancing the interneuron connections in cerebral cortex through a process that is similar to the developmental process happening in the brain. That is, a setting in which movements accompanied by music can facilitate neurotransmitter cycling responsible for stimulating the upper part of nervous system dealing with memory and cognition. Furthermore, the child in rhythmic play is required to obey some pre-determined patterns as the play rule that can provide an opportunity for memory scales, especially working memory, to improve if the patterns are repeated or practiced. Repetition of a rhythm in rhythmic movements can help children predict what will happen next, that is, the child with the help of his/her memory can predict the next components of a movement. To sustain the rhythm of rhythmic play can also improve the memory in intellectually disabled children and at the same time can reduce "memory function scales" problems.

To sum up, according to the above results, we can stipulate that rhythmically physical activities, a powerful therapeutic intervention (mediator), have a high potentiality to improve the memory and attention in educable children with intellectual disability. Especially when they are accompanied by music and song, they appear to be even more exciting and attractive to those children. Therefore, they can simply be included in educational and rehabilitation programs. They are important because they informally affect the quality of learning process in 
these children and improve their memory and attention which are the underlying assumption of learning process. It seems that rhythmic activities as an early mediator should be regarded as a new window in developing intellectually disable children's skills as they can affect cognitive, behavioral, emotional- affective skills. As an implication of this research, it would be better to investigate the effects of rhythmic play in pre-elementary levels.

\section{References}

[1] Alizadeh H. (2004). Attention deficit, hyper activity disorder (Persian), First edition. Tehran. Roshd publication; 2004.

[2] Anastazy A. (1976). Mental verification. Translation to persian: Mohammad Naqibaraheni. (1994). Tehran. Tehran University Press.

[3] Baddely A. D., Kopelman M. D., Willson B. A. (2002). The handbook of memory disorder ( 2 end). New York: Wiley.

[4] Bergen A., Mosley J., Am J Mental Retard 98(6) (1994) 732-743.

[5] Bratton S. C., Ray D., Rhine T., Jones L., Prof Psychological Res. 36(4) (2005) 376-90.

[6] Campbell S. C. (2008). Plays and its role in mental developmental, Retrieved, 10 June 2008, http://aarticledirectory.adsensepackages.com.

[7] Carr A., o'Relly G., Walsh P. N., McEvey J. (2007). The Handbook of Intellectuall Disability and Clinical psychology practice. First published 2007 by Routledge 27 church Rood. Hove. East Sussex BN32FA.

[8] Carmeli E., Josse F. T., Ariar C., Paz R., Sabbay H., Levy R., Sesori motor imperiments and sterategies in adults with intellectual disabilities motor control, 12 (2008) 348-361.

[9] Coe D. P., Pivarnik J. M., Womack C. J., Reeves M. J., Malina R. M., Medicie and sciencs in sport andexercise 38 (2006) 15-19.

[10] Davis C. L., Tomporowski P. D., Boyhe C. A., Wallev J. H., Miller P. H., Naglieri, J. (2007). Effect ofaerobic exercise on overweight children cognitive functioning a randomized controlled trail, Research Quarterly for Exercise and Sport.

[11] Eysenck M. E., Keane M. T. (2002). Cognitive Psychology. Translate Rahnama \& Faridi. London: Psychology Press.

[12] Farmer E. M. Z., Compton S. N., Burns B. J., Robertson E., J Consult Clin Psychol. 70(6) 92002) 1267-1302.

[13] Fryers, International Review of Research in Mental Retardation 22 (2006) 243-254.

[14] Goldshtrom Y., Korman D., Bendavid J. (2010). The effect of rhythmic exercise on cognition behavior of maltreated children: A pilot study 37, 50 Berdan Are. Fair lawn. NJ, 07710 USA.

[15] Haravandkhane F., Mir Zamane Bafghi S. M., Journal of Exceptional Children 29 (2009) 316-337.

[16] Hamm E. (2006). Playfulness and the Environmental Support of Play in Children Without Developmental Disabilities. OTJR: Occupation, Participation and Health. 
[17] Jadide M., Abedi. A. (2011). Conformity and standardization Neuropsychology Conner's questionnaire on children 5 to 12 years in Isfahan. Unpublished paper.

[18] Kakavand A. (2006). Morbid psychology of the child (Persian). Tehran: Publications Dvavyn, page 388.

[19] Kaplan H. I., Sadock V. A. (2007). Behavioral Sciences/Clinical Psychiatry.10 ${ }^{\text {th }}$ Ed, c2007.

[20] Kaplan R. S., Steele A. L., Journal of Music Therapy 42 (2005) 2-19.

[21] Kazemi F., Abedi A. (2011). Effectiveness Aerobic exercises of improve executive function and attention in children with learning disability esnerves - psychological, unpublished.

[22] Kenya S, Masal A. (2004). Rhythmic activates and initiatives for adulth Faciltators. Teachers and kids, Published in conjuction with funding.

[23] Keita Kamijo, Yoichi Hayashi, Tomoaki Sakai, TatsuhisaYahiro, Kiyoji Tanaka, Yoshiaki Nishihira (2008). Acute Effects of Aerobic Exerciseon Cognitive Function in Older Adults. Oxford Social the Volume. 356-363.

[24] Leisman G., Melillo R., Int J Disable Hum Dev 9(4) (2010) 275-282.

[25] Louhiala P. (2004). Preventing Intellectual Disability Ethical and Clinical Issues. Cambridge university press 2004.

[26] Massion J. (2006). Sport practice in autism. Scince \& Sports, 21, 243248. Meltzer L. (2007). Executive function in education: From theory to practice. N Y: Press. 2007; 66-88.

[27] Meltzer L. (2007). Executive function in education: From theory to practice. NY: Press. 2007; 66-88.

[28] Michałowski M. P., Kozima H. (2007). Methodological issues in facilitating rhythmic play with. 16 IEEE international conference on Ronot \& Human Interactive Communication.

[29] Piek J. P., Mieman A., Anderson M., The relationship between motor coordination executive functioning and attention in schoolaged children, Clinical neuropsychology 19 (2007).

[30] Rafee. T. (2003). Rhythmic movements and plays, guide for parent, education [Persion], puplish: Tehran, 2003.donjehpup.

[31] Raven J. C., Summers B. (1986). Manual for Ravens Progressive Matrices and Vocabulary Scale. Research Supplement, 3, London: Lewis.

[32] Robb S. L., J Music There 40(4) 92003) 266-82.

[33] Sadat Pour M., Mansour M., Effect of passive music and spontaneous movements in the mild mentally retarded children to curb aggression. Journal of Psychology 26(7) (2003).

[34] Shalev L., Yehoshua T., Mevorach C., Child Neuropsychology 13 (2007) 382-388.

[35] Sidman L. J., Clinical Psychology Review (2006) 466-485.

[36] Sutoo D., Akiyama K., Neurobiol. Dis. 13(1) (2003) 1-14.

[37] Valera E, Seidman L. J., Infants Young Child. 19(2) (2006) 94-108. 
[38] Whitley E., Ball J., Crit Care 6 (2002) 335-41.

[39] Wilson B. A. (2009). Memory rehabilitation: Integrating theory and practice. New York: The Guilford Press.

[40] Yukselen A., Dogan O., Turam F., Cetin Z., Ungan M., Effect of exercise for fundamental movement skill in mentally retarded child renmiddle. East of family medicine 6(5) (2008).

[41] Yosefi M., Reisi R., Alaei H., Pilehvarian, A., Journal of Isfahan Medical School 29(151) (2011). 